\title{
A Quantitative Literacy View of Natural Disasters and Nuclear
} Facilities

C. B. Connor

University of South Florida, cconnor@cas.usf.edu

Follow this and additional works at: https://digitalcommons.usf.edu/numeracy

Part of the Mathematics Commons, and the Science and Mathematics Education Commons

\section{Recommended Citation}

Connor, C. B.. "A Quantitative Literacy View of Natural Disasters and Nuclear Facilities." Numeracy 4, Iss. 2 (2011): Article 2. DOI: http://dx.doi.org/10.5038/1936-4660.4.2.2 


\title{
A Quantitative Literacy View of Natural Disasters and Nuclear Facilities
}

\author{
Abstract \\ The March 11, 2011 earthquake, tsunami, and nuclear disaster in Tohoku, Japan, highlights the need to \\ improve quantitative literacy $(\mathrm{QL})$ in natural hazard assessment. A critical understanding of natural hazard \\ assessments requires a sophisticated perspective on the mathematical and statistical tools used to \\ estimate the odds of disaster, and the roles of data quality, model development, and subjective probability \\ in estimation of uncertainty. Thus, improved QL is a basic requirement for improved decision-making \\ about the safety of critical infrastructure, such as nuclear facilities.

\section{Keywords} \\ Quantitative literacy, natural hazards, tsunami, earthquakes, Fukushima Dai-Ichi, probabilistic modeling \\ Creative Commons License \\ (c) (1) (9) \\ This work is licensed under a Creative Commons Attribution-Noncommercial 4.0 License

\section{Cover Page Footnote} \\ Chuck Connor is a geophysicist and volcanologist specializing in hazard assessment. He has worked with \\ the International Atomic Energy Agency since 1994 to develop guidelines for natural hazard assessment \\ to promote safe siting of nuclear facilities. He is a member of an international team that for 10 years has \\ advised the Nuclear Waste Organization of Japan on natural hazard assessment for a proposed \\ geological repository for radioactive waste. He is professor in the Department of Geology at the University \\ of South Florida, where he teaches Natural Hazards to general education students, Physical Volcanology \\ to upper-division undergraduates and first-year graduate students, and Potential Fields to advanced \\ graduate students.
}


According to the International Atomic Energy Agency (IAEA), there are more than 500 nuclear facilities operating on Earth today. If we sum the operating periods of these nuclear reactors, we find they have operated for more than 13,000 reactor-years. Nuclear facilities are commonly located in areas where external hazards from tropical cyclones, earthquakes, volcanic eruptions and the like are on the order of $10^{-4}$ to $10^{-5}$ per year. Given these numbers, we can react with dismay and horror to the impacts of the March 11, 2011 earthquake and tsunami on the Fukushima Dai-Ichi nuclear power plant, located in Tohoku, Japan, but we should not be overly surprised. Probability dictates that such events are expected, given the number of reactor-years already logged by this global industry.

Societies make decisions concerning public health and safety with a wide range of complex and competing metrics in mind, even in the best of circumstances. Are these decisions justified? To answer this, we need to accurately calculate the odds of disasters and their expected impacts. Such calculations are of course difficult and usually hampered by lack of precise information about the recurrence rates of catastrophic events and the potential magnitudes of these events. So, at its heart, assessment of natural hazards is an issue in quantitative literacy (QL). The informed public needs to understand the quantitative underpinnings of decisions. We need to understand the assumptions and limitations of these calculations. Perhaps more importantly, scientists and the public we serve need to understand the uncertainties inherent in calculating the odds. Since we live on a tectonically active planet, and we are building extreme technologies that carry the threat of regional, or perhaps global, impacts, we need to hone quantitative tools to render informed decisions and to evaluate these decisions.

Consider again the events of March 11. What was not expected following the earthquake and tsunami in Tohoku, Japan, is that containment would fail and that radionuclides would be released into the biosphere as a result of these external impacts. The U.S. Nuclear Regulatory Agency dictates that, for U.S. nuclear power plants, the probability of loss of containment due to such events should be less than $10^{-7}$ per year. That is, the facility should withstand external impacts in all but the rarest of circumstances. This is not a global standard. Indeed, a global regulatory standard does not exist today, as the IAEA has no mandate to establish regulations but only to issue guidelines on the safe siting of nuclear facilities. Nevertheless, if we expect that nations such as Japan should adhere to the highest safety standards then the consequences of the tsunami, direct release of radionuclides into the biosphere, was unexpected and unacceptable.

Certainly the Japanese public wishes for high standards. Anti-nuclear sentiment is higher in Japan than nearly anywhere else, largely due to their World War II experience with atomic holocaust. Yet Japan relies on nuclear power more than most nations, with 55 operating nuclear power plants and many more 
reactors. With few natural resources and high population density, Japan currently has no viable alternative to meet its energy needs. At the same time (and it's no geological accident), Japan is one of the most tectonically active nations on Earth. Located on the Pacific Ring of Fire, Japan has a high density of volcanoes and active faults. Consequently, Japan has invested heavily in monitoring the Earth. They have the world's best network of continuously operating global positioning system stations, used for measuring millimetric movements of the Earth's crust. They have dense networks of accelerometers and broadband seismometers. Nowhere else on Earth is so much known about the scale of movement and deformation of the crust than in Japan.

So how are they doing? Not well. Problems with external hazards in Japan's nuclear program did not start with the Fukushima Dai-Ichi disaster, nor do they seem likely to stop there. Consider the 2007 accident at the Kashiwazaki-Kariwa nuclear power plant, the largest nuclear power plant on Earth, producing 8000 MW of electricity for metropolitan Tokyo. A 6.8-magnitude (Richter scale) earthquake struck the area near this power plant in July, 2007. The geologic fault that slipped, producing the earthquake, is located offshore and went undetected by geologists and geophysicists prior to the earthquake. Although this accident was much less serious than the Fukushima Dai-Ichi accident, it did result in a small release of radiation into the Sea of Japan and shutdown of the nuclear power plant at a cost of billions of U.S. dollars. Public confidence was justifiably shaken, as analyses by geologists during the siting of this facility in the 1980s concluded there was no risk of such an event.

The Fukushima Dai-Ichi story is eerily similar. During siting of this 6-reactor nuclear power plant in the 1980s, earthquake and tsunami assessment concentrated on the area immediately adjacent to the nuclear power plant site. Large earthquakes (up to magnitude 8.3) were considered, originating where the Pacific ocean plate is subducted off the east coast of northern Japan. Following the Boxing Day tsunami of 2004, which killed approximately 240,000 people on the rim of the Indian Ocean, the IAEA requested that the Tokyo Electric Power Company reassess earthquake and tsunami hazards at their coastal nuclear facilities, including the Fukushima Dai-Ichi nuclear power plant. This hazard study was completed in 2007 and it was concluded that the maximum earthquake they considered, again a magnitude 8.3, would produce a tsunami of approximately $5.7 \mathrm{~m}$ height at the nuclear power plant site, and that a tsunami of this magnitude would be blocked from impacting the site by existing tsunami barriers - seawalls constructed in the 1980s. A report from the IAEA requested that measures be taken to reinforce the power plant cooling system against tsunami, but this request led to no change at the nuclear power plant site.

On March 11, the tsunami at the Fukushima Dai-Ichi nuclear power plant site reached 10-14 m, inundated much of the site, and destroyed the back-up cooling 
system, resulting in 10s, perhaps 100s of billions of U.S. dollars in damage and resulting in the catastrophic release of radiation. These events amplified the disaster, which had already caused horrific loss of life, and greatly complicated national and international relief efforts for survivors.

How can this happen? Both events, the Kashiwazaki-Kariwa earthquake and the Fukushima Dai-Ichi disaster following the tsunami illustrate the hubris of deterministic analyses of natural hazards. At both of these nuclear power plant sites, the worst case scenario was underestimated. It was assumed that difficult-todetect faults did not exist, and that the subduction zone would not trigger a magnitude-9 earthquake. A hallmark of deterministic analyses is that they truncate the tail of a distribution of potential events, either because it is convenient to ignore this tail or insufficient data are collected to describe it. In both the Kashiwazaki-Kariwa earthquake and the Fukushima Dai-Ichi tsunami, the disastrous events that eventually occurred were beyond expectation. This is a sure sign of inadequate hazard assessment.

Probabilistic methods applied to hazard assessment, of course, have their own issues. Which probability model best describes the geological process, such as the recurrence rate of hazardous events or their magnitudes? Are there enough data to sufficiently bound recurrence rates of disastrous events? But a huge advantage of probability distributions is that they have tails. If we use a Pareto or log-logistic model to describe a process, then we have to admit that rare, extreme events are possible, and we must plan accordingly.

What is the role of QL in improving our understanding of assessments of natural hazards? One of the most confusing aspects of hazard analysis is the possibility of very low probability events actually occurring. In daily life we are accustomed to assessing the odds of disaster, but on the scale of 1:9 (probability $10^{-1}$ ), or 1:999 (probability $10^{-3}$ ). For example, if our lifetime odds of dying of heart disease is 1:4, or of dying in a motorcycle accident is 1:999, many people would intuitively regard such odds as "high" and take steps to mitigate their risk of suffering these fates. The range of probabilities relevant in siting infrastructure, like nuclear power plants, or assessing the safety of communities, is many orders of magnitude less than these more tangible numbers. With this change in order of magnitude, most of us lose our intuitive sense of "high" or "low" probabilities. We need to be recalibrated.

Consider the following graph of the range of annual probability of hazards associated with living near volcanoes (Fig. 1). The graph spans eight orders of magnitude of annual probability. For some things, like roads or monitoring instruments, annual probability of destruction in the range of $10^{0}$ to $10^{-2}$ per year is acceptable. If erupting volcanoes destroy these things we will rebuild them, generally without much difficulty. For example, the southern Ring Road in Iceland crosses areas prone to volcanic activity, and portions of this major road 
must be rebuilt every 10-20 years due to volcanic activity. On the other hand, whole communities, hopefully, are not exposed to hazards of this order of magnitude. Worldwide, many communities are exposed to hazards with annual probabilities of $10^{-6}$ to $10^{-3}$ due to earthquakes, tsunami, volcanic activity and the like. Generally, when probabilities are on the order of $10^{-3}$ per year or higher, steps are taken to mitigate hazards. For example, communities have installed debris-flow monitoring networks on the west slope of Mt. Rainer volcano, Washington, in order to gain precious time to react in case of volcanic activity expected there with an annual probability on the order of $10^{-3}$. The range associated with annual probability of destruction of communities by volcanoes represents the variation in what is considered to be "acceptable risk" worldwide.

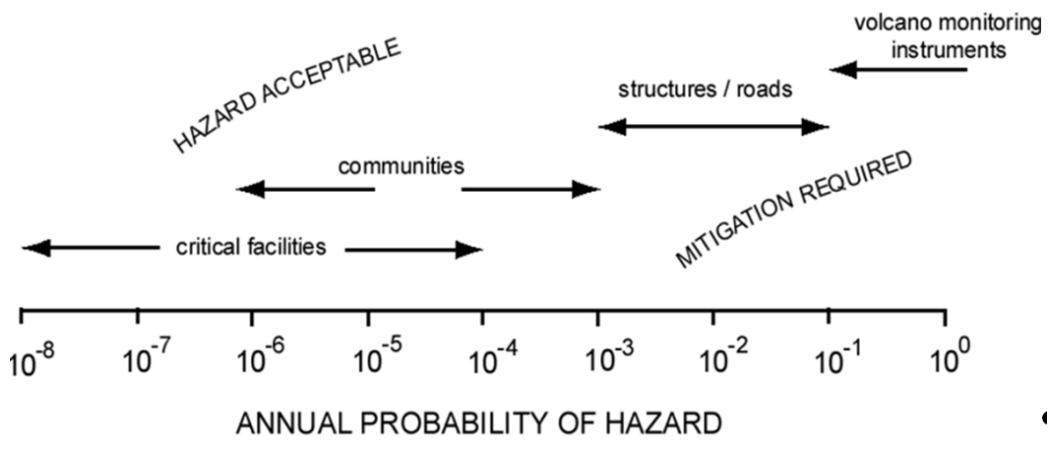

Figure 1. The range of annual probability associated with specific types of infrastructure, communities and facilities. Orders of magnitude variation in acceptable hazard rates occur depending on the type of infrastructure or community considered. The lengths of the double arrows represent variation, worldwide, in acceptable hazard rates.

On the other hand, critical facilities, such as nuclear power plants, can be sited in the areas we choose, within limits, and so the acceptable hazard is yet lower. In addition, it is widely acknowledged that destruction of such facilities may have impact well beyond the immediate area, and so higher standards are expected than are associated even with the potential destruction of communities. In some regions, such as Japan, nuclear power plants are built where the possibility of destruction by volcanoes is on the order of $10^{-5}$ per year, such as on the island of Kyushu. In such circumstances, an annual probability of $10^{-5}$ might be considered to be "high," as the consequences of destruction of the site for society are potentially so large. By these metrics, it is abundantly clear that the probability of earthquake and tsunami impact on Fukushima Dai-Ichi was much greater than is normally considered acceptable. Only the truncation of the distribution by deterministic consideration of maximum anticipated events led to siting of this facility on the east coast of Tohoku. For very long-lived facilities, such as geological repositories of radioactive waste, annual probabilities of 
destruction on the order of $10^{-7}-10^{-8}$ are often considered to be of concern.

If understanding the meaning of probability estimates is a challenge in QL, understanding the data, models, and assumptions used to make these probabilistic estimates is even more challenging to understand. In the 1960s, Allin Cornell revolutionized the discipline of probabilistic seismic hazard assessment by distinguishing between aleatoric uncertainty and epistemic uncertainty (Cornell, 1968). Aleatoric uncertainty refers to the random variations in natural systems that make them impossible to predict. Because the rate and magnitudes of earthquakes are not regular in time, we must develop statistical forecasts of these phenomena. Easy enough. But Cornell also pointed out that we should evaluate epistemic uncertainty as a separate issue. Epistemic uncertainty arises from uncertainty about the validity of models we use. Is the distribution of hazardous events best characterized by a Poisson model or a Pareto model? What is our confidence in models of tsunami height, given the source magnitude and mechanisms associated with a tsunami-genic earthquake? Such epistemic uncertainty essentially makes forecasts of natural disasters more subjective.

How do we fold uncertainty in models into our probabilistic hazard assessments? One method that is increasingly used in assessment of natural hazards is to ask experts to weight models and data to develop a subjective probability. For example, consider the graph in Figure 2. Eight experts, selected

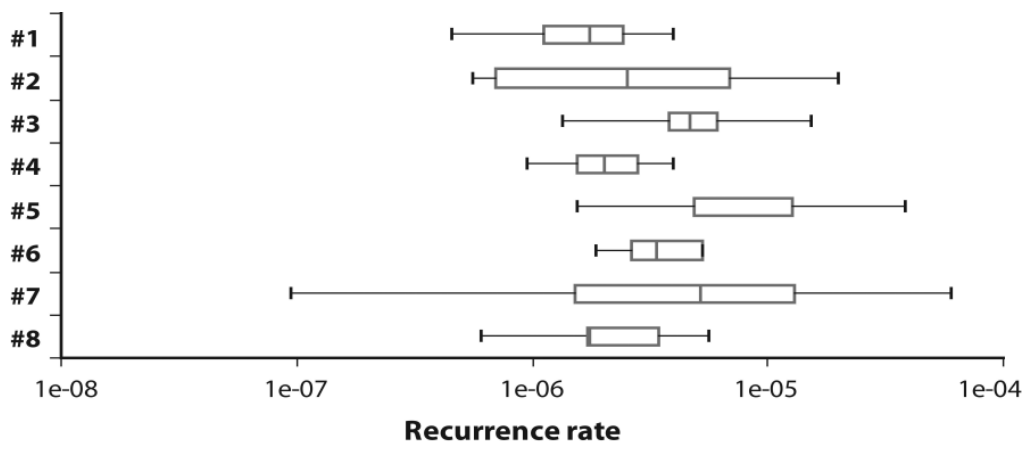

Figure 2. Subjective probability of hazardous events can be estimated using expert elicitation. Here eight experts were asked to estimate the recurrence rate of volcanic activity for the region about Yucca Mountain, Nevada, the proposed site of a high-level radioactive waste repository. The results, for each expert, are represented by the box and whisker plots. The aggregate probability is thought to better represent the true uncertainty of the hazard estimate (from Coppersmith et al., 2009).

from a larger pool of scientists, were asked to assess the recurrence rate of volcanic activity near Yucca Mountain, Nevada, the proposed site of a high-level radioactive waste repository. Unfortunately, the site is located in an area of 
volcanic activity, meaning that there is a credible potential for new volcanoes to erupt through a facility if it were built at Yucca Mountain. The eight experts considered aleatoric uncertainty, for example the known timing of past volcanic events in the region, and considered various models of volcanic activity. Perhaps ironically, because the rate of volcanic activity in the region is low, there is also considerable uncertainty about the rate. The probability assigned to recurrence rates by each expert is represented by box and whiskers plots (Fig. 2). The idea of such subjective probability estimates is that the aggregate probability, calculated by combining the eight box and whisker plots, better represents the true uncertainty in recurrence rate estimates for volcanism. Inspection of Figure 2 does reveal that there is central tendency in the aggregate of the probabilities, with most estimates falling between $10^{-5}$ and $10^{-6}$ per year. There also is tremendous range, spanning about four orders of magnitude, in estimates of the recurrence rate. This outcome is typical of subjective probability estimates and is thought to reflect our true uncertainty.

Note that this analysis, although subjective, captures the long tail of the distribution. This is a fundamental difference between probabilistic methods, including the subjective probabilities estimated through expert elicitation, and deterministic methods. In a deterministic assessment, experts might be called upon to describe hazard scenarios for a site, or worse yet, to declare a site safe from natural hazards or not. Such an approach results in the siting of facilities in unsafe locations. Probabilistic assessment, with all its complexities and potential pitfalls, offers a robust alternative, with experts relied upon to estimate parameter distributions, assess the validity of models, and evaluate data in order to arrive at an expected value of hazard and a thorough understanding of the uncertainties. A quantitatively literate public should be able to distinguish between subjective probability estimated through expert judgment and flawed deterministic assessments. Arguably, our lives and our planet depend on it.

\section{References}

Coppersmith, K. J., K. E. Jenni, R. C. Perman and R. R. Youngs. 2009 Formal expert assessment in probabilistic seismic and volcanic hazard analysis, In Volcanic and tectonic hazard assessment for nuclear facilities, ed. C. B. Connor, N. A. Chapman and L. J. Connor, 593-611. Cambridge University Press.

Cornell C.A. 1968. Engineering seismic risk analysis. Bulletin of the Seismological Society of America, 58(6): 1583-1606. 